\title{
ADENOSINO-DEAMINASE NO LÍQUIDO CELALORRAQUEANO DE PACIENTES COM A SÍNDROME DA IMUNODEFICIÊNCIA ADQUIRIDA
}

\author{
LUÍS DOS RAMOS MACHADO, * JOSÉ ANTONIO LIVRAMENTO, * * ANTONIO SPINA-FRANÇA * *
}

RESUMO - A determinação da atividade enzimática da adenosino-deaminase (ADA) no líquido cefalorraqueano (LCR) de pacientes com síndrome da imunodeficiência adquirida (AIDS) pode sinalizar, ainda que de modo inespecífico, a atividade de patologias associadas. Os níveis de atividade de ADA, estudados no LCR de 263 pacientes, estavam aumentados naqueles com patologias associadas em relação aos controles normais e em relaçāo aos pacientes com AIDS que não apresentam alterações ao exame de LCR. No entanto, os níveis de ADA detectados no LCR não apresentaram diferença estatística ao se considerarem os seguintes grupos de pacientes distribuídos segundo os achados no próprio LCR: com anticorpos para toxoplasmose, sífilis ou citomegalovírus; com $C$. neoformans ou seus antígenos; com bacilos álcool-ácido-resistentes; com linfomas.

PALAVRAS-CHAVE: adenosino-deaminase, líquido cefalorraqueano, AIDS (SIDA), citomegalovírus, criptococose, sífilis, toxoplasmose, tuberculose, linfoma.

Adenosine-deaminase in the cerebrospinal fluid of patients with the acquired immunodeficiency syndrome

SUMMARY - The adenosine-deaminase (ADA) activity was evaluated in CSF samples from 263 patients with AIDS. An elevated ADA activity in CSF was found in patients with: antibodies to toxoplasmosis, syphilis or cytomegalovirus; Cryptococcus neoformans or their antigens; tuberculous meningitis; lymphoma. There was no statistical difference among all these groups in respect to ADA activity. However, the ADA activity in CSF from AIDS patients without CSF changes other than HIV antibodies, even unspecific changes, was not elevated. This may suggest that ADA is related to AIDS associated pathologies activity rather than to HIV infection itself.

KEY-WORDS: adenosine-deaminase, cerebrospinal fluid, AIDS, cytomegalovirus, cryptococosis, toxoplasmosis, tuberculous meningitis, syphilis, lymphoma.

Adenosina deaminase (ADA) é enzima envolvida no catabolismo das purinas, particjpando na via de transformaçăo da adenosina em inosina. Encontra-se em vários locais do organismo, desempenhando funções importantes em órgãos linfóides. Uma de suas isoenzimas parece estar associada à atividade de células T (células CD4), enquanto outra isoenzima parece relacionar-se à atividade de macrófagos ${ }^{3,13,15}$. A atividade de ADA pode, portanto, sinalizar a ocorrência de processos inflamatórios, seja marcando o aumento da atividade intracelular em macrófagos que acompanha os fenômenos de fagocitose, seja expressando ou marcando a ativação das células CD4 e o consequente desencadear da reaçāo inflamatória em cascata'.

O objetivo deste estudo é relatar os níveis de atividade de ADA observados no LCR de pacientes com AIDS.

*Professor Assistente, **Professor Docente-Livre e ***Professor Titular Emérito do Departamento de Neurologia da Faculdade de Medicina da Universidade de São Paulo. Aceite: 27-julho-1995

Dr. Luís dos Ramos Machado - Praça Amadeu Amaral 47 conj 33 - 01327-010 São Paulo SP - Brasil. FAX 0112898879 


\section{CASUÍSTICA E MÉTODOS}

Foram estudadas as amostras de LCR de 263 pacientes com AIDS, entre dezembro-1992 e junho-1995. Todos apresentavam, por ocasião do exame, alterações clínicas que justificaram a feitura do exame de LCR.

Foram incluídas no estudo, de modo sucessivo e sem outra seleção que não os critérios de inclusão, as amostras de LCR nas quais foi possível detectar a presença de anticorpos para toxoplasmose, sífilis ou citomegalovirose (CMV). Foram incluídas também aquelas amostras que evidenciavam: presença de Cryptococcus neoformans ou de seus antígenos; presença de bacilos álcool-ácido-resistentes (BAAR). Foram incluídos ainda: um grupo de pacientes com linfomas; um grupo de pacientes com AIDS nos quais o exame de LCR se encontrava dentro dos limites normais, sem evidência de neoplasia ou processo infeccioso associado. Em todos os pacientes foram detectados anticorpos anti-HIV no LCR.

As patologias associadas à AIDS consideradas neste estudo, bem como o respectivo número de pacientes sāo referidos na Tabela 1.

As amostras de LCR foram submetidas a análise completa, incluindo: exame citológico e citomorfológico; estudo das proteínas e suas fraçōes; determinação de concentração de cloro e de glicose; exarnes bacteriológico, micológico e micobacteriologico diretos; pesquisa de antígenos do Cryptococcus neoformans; pesquisa de anticorpos para sífilis, cisticercose, toxoplasmose, doença de Chagas, tuberculose, histoplasmose, paracoccidioidomicose, candidíase, aspergilose, CMV, Herpes simplex tipo 1, Herpes simplex tipo 2, Varicelazóster e HIV; culturas para bactérias, fungos e BAAR.

A atividade de ADA foi determinada segundo o método colorimétrico de Giusti ${ }^{5}$. Foram considerados como dentro dos limites normais os valores até 4,5 unidades $/ \mathrm{L}$.

São relatados as médias e desvios padrões, as medianas e os intervalos de variação. Para análise estatística, foram utilizados os testes de Mann-Whitney-Wilcoxon e de Kruskal-Wallis.

\section{RESULTADOS}

Os valores das medianas, médias, desvios padrōes e intervalos de variação para cada uma das patologias estudadas constam da Tabela 2.

Não houve diferença estatisticamente significativa entre os níveis de atividade de ADA registrados, seja em pacientes com patologias isoladas $(T=5,60 ; p=0,23)$, seja em pacientes com mais de uma patologia $(T=6,65 ; p=0,25)$. Este tipo de comportamento estatístico também não variou ao serem incluídos os pacientes com linfomas ( $\mathrm{T}=9,14 ; \mathrm{p}=0,17)$. Portanto, os níveis de atividade de ADA determinados em pacientes com AIDS e patologias infecciosas ou infiltraçōes meníngeas por linfomas associadas apresentam caráter inespecífico, nāo sendo possível relacionar níveis de atividade a tipos específicos de patologias.

Tabela 1. Patologias Associadas à AIDS.

\begin{tabular}{clc}
\hline Grupo & Elementos diagnósticos & $N^{0}$ de casos \\
\hline 1 & Anticorpos anti-T. gondii (IgG) & 87 \\
2 & C. neoformans ou seus antígenos & 56 \\
3 & Anticorpos anti $-T$. pallidum (IgG) & 19 \\
4 & Anticorpos anti-citomegalovírus & 11 \\
5 & Bacilos álcool -ácido resistentes & 8 \\
6 & Associação de elementos diagnósticos & 28 \\
7 & Infiltração meníngea em linfomas & 22 \\
\hline
\end{tabular}


Tabela 2. Niveis de atividade de ADA no LCR.

\begin{tabular}{ccccc}
\hline Grupo & Mediana & Média & Desvio padrão & Intervalo de variação \\
\hline \hline 1 & 7,0 & 10,5 & 8,98 & $0,4-47$ \\
2 & 9,2 & 12,5 & 9,48 & $2,4-30$ \\
3 & 8,8 & 11,1 & 8,87 & $1,8-34$ \\
4 & 6,7 & 8,3 & 5,94 & $2,9-22$ \\
5 & 15,6 & 21,9 & 17,96 & $2,7-47$ \\
6 & 9,8 & 12,3 & 8,56 & $1,3-39$ \\
7 & 6,3 & 9,0 & 7,84 & $1,0-30$ \\
8 & 2,5 & 2,5 & 1,15 & $0,4-4,45$ \\
\hline
\end{tabular}

Considerados isoladamente, os níveis de ADA registrados em pacientes com neurotuberculose também não foram diferentes, do ponto de vista estatístico, daqueles registrados para o conjunto das outras patologias $(Z=1,07 ; p=0,17)$.

Quando não há outras alterações ao exame de LCR que não a presença de anticorpos antiHIV, a atividade de ADA registrada no LCR de pacientes com AIDS apresenta-se dentro dos limites normais determinados para pacientes imunocompetentes. Esta atividade é substancialmente menor do que aquela verificada nas outras patologias associadas à AIDS, consideradas em seu conjunto $(Z=7,58 ; p<0,001)$.

\section{COMENTÁRIOS}

Aumento da atividade de ADA no LCR tem sido considerado quase patognomônico de meningoencefalite tuberculosa. No entanto, pode ocorrer também aumento da atividade de ADA em pacientes com linfomas e leucemias (especialmente de células $T$ ), em neurosarcoidose, em meningites bacterianas graves ou complicadas, em neurobrucelose, em neurocriptococose e no soro de pacientes com AIDS. Há, ainda, relato isolado de aumento da ativiuade de ADA em paciente com hemorragia subaracnóidea ${ }^{2,4,6}$. Alguns autores consideram haver forte vinculaçāo entre níveis elevados cue atividade de $\mathrm{ADA}$ e neurotuberculose, constituindo-se os níveis acima de 21 unidades/L como fortemente sugestivos ${ }^{5,7,10,11,12}$.

A determinação da atividade de ADA no LCR é feita através de método simples e pouco dispendioso. Apesar de sua inespecificidade, pode desempenhar importante papel de triagem. Frequentemente permite, com razoável grau de confiança, distinguir entre meningites agudas (virais ou bacterianas) e processos meningoencefalíticos, mesmo em sua fase inicial de apresentação. Nos primeiros, o nível de atividade de ADA é normal; nos segundos, essa atividade está aumentada. Meningites aparentemente assépticas ou a vírus, quando acompanhadas de aumento de ADA, devem colocar o médico de sobreaviso e implicam em estender a investigação para excluir patologias como neuroturbeculose, neuromicoses ou mesmo infiltração meníngea por linfomas ou leucemias ${ }^{9.12 .14 .}$

É evidente a importância da determinação da atividade da ADA no LCR de pacientes com AIDS, frequentemente acometidos por infeç̧ões oportunísticas. Há, no entanto, dúvidas ainda nāo esclarecidas quanto a possíveis fatores que poderiam interferir nos resultados. Pode ser considerado como fator fundamental o acometimento das células CD4 pelo HIV. Como este acometimento é de natureza complexa e de tipo funcional, a interferência da infecção pelo HIV na atividade de ADA, se confirmada, pode não acontecer de modo linear, tomando-se difícil validar inferências diagnosticas a partir de observaçōes feitas em pacientes imunocompetentes. 
Os resultados deste estudo podem ajudar a esclarecer alguns dos aspectos mencionados. A vigência de processos infecciosos do sistema nervoso parece ser sinalizada de modo semelhante nos pacientes com AIDS e nos imunocompetentes. Nāo é possível, entretanto, inferir, em pacientes com AIDS, o tipo de patologia envolvido, considerando exclusivamente os níveis de atividade de ADA, já que os níveis são semelhantes em todas as patologias estudadas.

Havia em todos os grupos algumas variáveis, consideradas essenciais na conceituação de atividade inflamatória, dentro dos limites normais. Entre essas variáveis são considerados: o número de células, a presença de polimorfonucleares, o aumento do teor de proteínas ou a presença dos anticorpos ou dos antígenos mais frequentemente encontrados em pacientes com AIDS. Ocorrendo de modo assimétrico ou disarmônico, a resposta inflamatória apresenta-se muitas vezes incompleta. Esta assimetria não interferiu com a atividade de $\mathrm{ADA}$, que persistiu em níveis estatisticamente mais elevados apesar da ocasional normalidade de algumas das variáveis referidas.

Foi estudado, em separado, um grupo de pacientes que apresentavam todo o exame de LCR rigorosamente dentro dos limites normais, exceção feita à presença de anticorpos anti-HIV. Todos estes pacientes, nos quais não foi possível detectar qualquer alteração ao exame de LCR, específica ou inespecífica, apresentavam a atividade de ADA dentro dos limites normais. Os níveis normais de ADA nestes pacientes mostram que as alterações observadas quanto ao nivel de atividade de ADA em pacientes com AIDS não estão relacionadas ao HIV, mas à vigência de patologias associadas.

Esta informaçăo é fundamental, pois permite discriminar dois grupos de pacientes: aqueles com ADA em níveis elevados e que possivelmente apresentam processos infecciosos ou linfomas em atividade no sistema nervoso, associados à AIDS; e aqueles com ADA em níveis normais e que possivelmente não apresentam aquelas patologias em fase ativa.

Deve ser realçado que estas informaçōes só podem ser obtidas quando se realiza o exame completo do LCR, de modo sistematizado, incluindo o exame clássico c a pesquisa cuidadosa pelo menos das patologias mais frequentemente associadas à $\operatorname{AIDS}^{7,8}$.

Marcadores habituais de atividade inflamatória numericamente dentro dos limites normais podem, portanto, refletir não um estado de não-infecção, mas o bloqueio da expressão do processo infeccioso pelo HIV. O reconhecimento e o distinguir destas duas situaçōes torna-se muitas vezes difícil.

É neste contexto que, em pacientes com AIDS, ganha maior significado um teste tão simples quanto a determinação da atividade da ADA. Ainda que inespecífico, este teste permite sinalizar a vigência de processos infecciosos mesmo em condições nas quais a expressāo de outros marcadores pode estar bloqueada.

\section{REFERÊNCIAS}

1. Carilaos G, Calia GM, Naitana AG. Adenosine deaminase (ADA) activity in cerebrospinal fluid. Scand J Infect Dis 1992, 24:121-122.

2. Chawla RK, Set RK, Raj B, Saini AS. Adenosine deaminase levels in cerebrospinal fluid in tuberculosis and bacterial meningitis. Tubercle 1991, 72:190-192.

3. Egido JA, Gonzales JL, Cubo E. False positive of ADA determination in cerebrospinal fluid. Acta Neurol 1994, 16:288-290.

4. Giblett ER, Anderson JE, Cohen F, Pollara B, Meuwissen HJ. Adenosine deaminase deficiency in two patients with severely impaired cellular immunity. Lancet 1972, 2:1067-1069.

5. Giusti G. Adenosine deaminase. In Bergmeyer HU. (ed). Methods of enzymatic analysis. New York: Academic Press., 1974, p1092-1099..

6. Inigo MA, Rui Lopez de Tejada M, Torres-Tortosa M, Sanchez-Porto A, Ugarte J, Garcia de Lomas E, Moran Nestares A. Serum adenosine deaminase in human immunodeficiency virus infection: its relationship with CD4 lymphocytes and B2 microglobulin. Med Clin (Barc) 1992, 99:766-768.

7. Livramento JA, Machado LR, Gomes HR, Vianna LS, Spina-França A. AIDS: a CSF laboratory experience on 470 cases in a 7 year time period. Arq Neuropsiquiatr 1992, 50:56-59. 
8. Livramento JA, Machado LR, Nóbrega JPS, Spina-França A. AIDS: a CSF laboratory experience on 610 cases in a 8 year time period. Can J Neurol Sci 1993, 20(Suppl 4):S118.

9. Malan C, Donald PR, Golden M, Taljaard JJF. Adenosine deaminase levels in cerebrospinal fluid in the diagnosis of tuberculous meningitis. J Trop Med Hyg 1984, 87:33-40.

10. Meyers BR. Tuberculous meningitis. Med Clin North Am 1982, 66:755-762.

11. Ocaña I, Martinez-Vazquez JM, Ribera E, Segura RM, Pascual C. Adenosine deaminase activity in the diagnosis of lymphocytic pleural effusions of tuberculous, neoplastic and lymphomatous origin. Tubercle 1986, 67:141-145.

12. Piras MA, Gakis C. Cerebrospinal fluid adenosine deaminase activity in tuberculous meningitis. Enzyme 1973, 14:311-317.

13. Ribera E, Martinez-Vazques JM, Ocana I, Segura R, Pascual C. Activity of adenosine deaminase in cerebrospinal fluid for the diagnosis and follow up of tuberculous meningitis. J Infect Dis 1987, 155:603-607.

14. Segura RM, Pascual C, Ocana I, Martin-Vazquez JM, Ribera E, Ruiz I, Pelegri MD. Adenosine deaminase in body fluids: a useful diagnostic tool in tuberculosis. Clin Biochem 1989, 22:141-148.

15. Sullivan JL, Osborne WRA, Wedgwood RJ. Adenosine deaminase activity in lymphocytes. Br J Haematol $1977,37: 157-158$. 